\title{
Lithographic patterning of ferromagnetic FePt nanoparticles from a single-source bimetallic precursor containing hemiphasmidic structure for magnetic data recording media
}

\author{
Zhengong Meng ${ }^{1,3}$, Cheuk-Lam $\mathrm{Ho}^{2,3^{*}}$, Hon-Fai Wong ${ }^{4}$, Zhen-Qiang $\mathrm{Yu}^{{ }^{1 *}}$, Nianyong Zhu ${ }^{3}$, \\ Guijun $\mathrm{Li}^{4}$, Chi-Wah Leung ${ }^{4 *}$ and Wai-Yeung Wong ${ }^{1,2,3^{*}}$
}

\begin{abstract}
Patterning of $\mathrm{L1}_{0}$ FePt nanoparticles (NPs) with high coercivity offers a promising route to develop bit-patterned media (BPM) for the next generation magnetic data recording system, but the synthesis of monodisperse FePt NPs and mass production of their nanopatterns has been a longstanding challenge. Here, highly efficient nanoimprint lithography was applied for large-scale universal patterning, which was achieved by imprinting the solution of a single-source bimetallic precursor. The rigid coplanar metallic cores and the surrounding flexible tails in the bimetallic complex permit the spontaneous molecular arrangements to form the highly ordered negative morphology replicated from the soft template. In-situ pyrolysis study was then investigated by one-pot pyrolysis of the precursor under an $\mathrm{Ar} / \mathrm{H}_{2}$ atmosphere, and the resultant NPs were fully characterized to identify the phase, morphology and magnetic properties. Finally, highly-ordered patterns on certain substrates were preserved perfectly after pyrolysis and could be potentially utilized in magnetic data recording media.
\end{abstract}

Keywords: FePt nanoparticles; single-source bimetallic precursors; one-pot pyrolysis; lithographic patterning; magnetic data recording media

\section{INTRODUCTION}

Magnetic nanoparticles (NPs), owing to their designable functional properties, are regarded as an important class of artificial nanostructured materials in various fields, such as electrocatalysis, magnetic data storage, and biomedical applications [1-11]. Monodisperse $\mathrm{L}_{0}$ FePt NPs with nearly equal atomic ratio exhibit high magnetocrystalline anisotropy and have a chemically ordered facecentered tetragonal (fct) structure [12], which are also considered as the prospective activated materials for the next-generation data storage system [13].

While the properties of FePt NPs are closely related to their dimensions, compositions, and structures, great efforts on controlling the size, shape, composition and structure of FePt NPs as well as their specific functionality for certain targeted applications have been made [14]. Generally, preparation of FePt NPs could be achieved by vacuum deposition techniques, gas phase evaporation and organic phase synthesis, etc. Since Sun et al. [15] firstly reported the synthetic method of FePt NPs by combining high temperature pyrolysis of $\mathrm{Fe}(\mathrm{CO})_{5}$ with chemical reduction of $\mathrm{Pt}(\mathrm{acac})_{2}$, organic phase syntheses have been widely used to prepare FePt, FePd and CoPt NPs, owing to the distinct advantages over conventional physical methods $[16,17]$. Alternative counterparts of the unstable iron source were also sought, such as $\mathrm{Fe}(\mathrm{acac})_{3}$ and $\mathrm{FeCl}_{3}$, etc $[14,18]$. To better control the ratio of Fe and Pt ions in NPs, single-source precursors containing iron and platinum atoms in a single molecule were designed and synthesized [19-21]. Also, various attempts have been made

\footnotetext{
${ }^{1}$ College of Chemistry and Environmental Engineering, Shenzhen University, Shenzhen 518060, China

${ }^{2}$ Department of Applied Biology and Chemical Technology, The Hong Kong Polytechnic University, Hung Hom, Hong Kong, China

${ }^{3}$ Institute of Molecular Functional Materials and Department of Chemistry, Hong Kong Baptist University, Waterloo Road, Kowloon Tong, Hong Kong, China; HKBU Institute of Research and Continuing Education, Shenzhen Virtual University Park, Shenzhen 518057, China

${ }^{4}$ Department of Applied Physics, The Hong Kong Polytechnic University, Hung Hom, Hong Kong, China

* Corresponding authors (emails: zqyu@szu.edu.cn (Yu ZQ); wai-yeung.wong@polyu.edu.hk (Wong WY); cheuk-lam.ho@polyu.edu.hk (Ho CL); apleung@polyu.edu.hk (Leung CW))
} 
to directly prepare the $\mathrm{L}_{0}$ FePt NPs by a one-step approach [22], and some approaches of avoiding particle sintering during post-annealing were developed, such as by lowering the transformation temperature from facecentered cubic ( $f c c)$ phase to fct phase [23] or mixing the sources with finely grounded $\mathrm{NaCl}$ to protect NPs from agglomeration $[24,25]$. Recently, our group has developed an alternative method for synthesizing $\mathrm{Ll}_{0} \mathrm{FePt}$ NPs with high dispersity by the one-step pyrolysis, which relied on the intelligent design of some bimetallic precursors [2630]. Such method can produce fct phase NPs without further thermal annealing and allow their patterning on a large scale easily by lithographic methods [6-8].

Patterning of the FePt NPs on a certain substrate is the key point to extend their application in bit-patterned media (BPM), in which one separate bit is located in every magnetic island, and such approach had a bright future for magnetic data recording to enhance the data storage density [31]. Although periodic arrays of $\mathrm{FePt}$ NPs could be obtained by self-assembly [13], there is still a big challenge for their mass production. We have tried to introduce the lithographic approach to prepare regular arrays and tested for their potential in magnetic data recording system after pyrolysis, but only mechanically robust polymers have been investigated successfully till now $[6,7]$. It is still hard to form ordered patterns by using small molecules. As we know, polymer materials can be easily patterned by nanoimprinting lithography (NIL); however, it is typically difficult to use small molecules in preparing ordered morphology due to the poor processability. Considering that certain orientation of small molecular liquid crystals can be achieved by special structural design, we integrated here the idea of using single-source bimetallic precursors with the hemiphasmidic structure of the ligand to obtain highly ordered patterns of NPs, which can further provide magnetic patterns after pyrolysis. This is the first time to extend the NIL technique to prepare ordered arrays by a small molecular organometallic complex instead of an organometallic polymer. Such molecular design with hemiphasmidic structure can induce and promote the spontaneous arrangements to prepare a certain morphology which is a negative copy replicated from the soft template during the lithographic process. Ferrocenefunctionalized $\mathrm{Pt}(\mathrm{II})$ complexes with coplanar hemiphasmidic structure have been demonstrated to be intelligent materials showing excellent processability with versatile applications [32-34].

In this work, a novel dendrimer-like molecule $\mathbf{1}$ was prepared from a neutral Fe,Pt-containing bimetallic complex 2 with a tridentate chelating ligand 6-(4-(tertbutyl)phenyl)-4-ferrocenyl-2,2'-bipyridine, where the ligand can bind to $\mathrm{Pt}(\mathrm{II})$ ions easily to give the neutral complex 2 with good solubility. After further introducing the three octyl chains in $\mathbf{1}$, the processability for subsequent patterning studies was greatly enhanced. Both of the bimetallic complexes were used as single-source precursors to obtain FePt NPs and the relationships between the properties of the resultant FePt NPs and their chemical structures of the two different precursors were studied. In addition, highly ordered patterns of FePt NPs suitable for magnetic data recording media were imprinted on the silicon substrate by the mass productive NIL method.

\section{EXPERIMENTAL SECTIONS}

\section{General procedures and materials}

All reactions were carried out under nitrogen unless otherwise stated. Commercially available reagents were used as received without further purification. 3,4,5-Tris (octyloxy)benzyl alcohol was synthesized according to the modified literature method [35]. All reactions were monitored by thin-layer chromatography (TLC) with Merck pre-coated glass plates. Compounds were visualized with UV light irradiation at 254 and $365 \mathrm{~nm}$. Purification of products was achieved by column chromatography. NMR spectra were measured in $\mathrm{CDCl}_{3}$ on a Bruker AV 400 NMR instrument with chemical shifts being referenced against tetramethylsilane as the internal standard for ${ }^{1} \mathrm{H}$ and ${ }^{13} \mathrm{C}$ NMR data.

For the single-crystal analysis of 2, X-ray diffraction data were collected at $173 \mathrm{~K}$ using graphite-monochromated Mo-Ka radiation $(\lambda=0.71073 \AA)$ with a Bruker APEX II CCD diffractometer. The collected frames were processed with the software SAINT+ and an absorption correction (SADABS) was applied to the collected reflections. The structure was solved by direct methods (SHELXTL) in conjunction with standard difference Fourier techniques and subsequently refined by full-matrix least-squares analyses on $\mathrm{F}^{2}$. Hydrogen atoms were generated in their idealized positions and all nonhydrogen atoms were refined anisotropically. CCDC1562137 contains the supplementary crystallographic data for this paper. These data can be obtained free of charge from The Cambridge Crystallographic Data Center via www.ccdc.cam.ac.uk/data_request/cif.

The structural characterization of the as-synthesized FePt NPs was performed by powder X-ray diffraction (PXRD) on a Bruker D8 machine with $\mathrm{Cu} \mathrm{K}_{\mathrm{al}}(\lambda=$ 
$1.541 \AA, 40 \mathrm{kV}, 30 \mathrm{~mA}$ ) for analyzing the composition and phase purity of the resulting NPs [36,37]. Transmission electron microscopy (TEM) analysis was carried out on a Philips Tecnai G2 20 S-TWIN for probing the morphology, particle size and size distribution of the NPs. Energy dispersive X-ray (EDX) spectra were obtained on a LEO 1530 SEM to study the ratio of Fe and Pt in the resultant metal alloy NPs. The morphology of the asprepared arrays of $\mathrm{L}_{0}$ phase FePt NPs was investigated by a LEO 1530 scanning electron microscope (SEM). The magnetic hysteresis loops at room temperature were measured by a quantum design physical property measurement system (PPMS).

\section{Synthesis of organometallic precursors}

L1: To the solution of ferrocenecarboxaldehyde $(2.14 \mathrm{~g}$, $10 \mathrm{mmol}$ ) in $15 \mathrm{~mL}$ of ethanol, 4-tert-butylacetophenone $(1.76 \mathrm{~g}, 10 \mathrm{mmol})$ and $\mathrm{NaOH}(0.60 \mathrm{~g}, 15 \mathrm{mmol})$ were added. The mixture was stirred for $2 \mathrm{~h}$ at room temperature to get a red precipitate. The solid was filtered off and washed with water. The product was collected and dried as a red solid $(2.9 \mathrm{~g}, 91 \%) .{ }^{1} \mathrm{H} \mathrm{NMR}\left(\mathrm{CDCl}_{3}\right.$, $400 \mathrm{~Hz}, \delta / \mathrm{ppm}): 7.93$ (s, $2 \mathrm{H}), 7.74(\mathrm{~d}, J=13.6 \mathrm{~Hz}, 1 \mathrm{H})$, $7.51(\mathrm{~s}, 2 \mathrm{H}), 7.14(\mathrm{~d}, J=14 \mathrm{~Hz}, 1 \mathrm{H}), 4.60(\mathrm{~s}, 2 \mathrm{H}), 4.48(\mathrm{~s}$, $2 \mathrm{H}), 4.17(\mathrm{~s}, 5 \mathrm{H}), 1.36(\mathrm{~s}, 9 \mathrm{H}) .{ }^{13} \mathrm{C} \mathrm{NMR}\left(\mathrm{CDCl}_{3}, 100 \mathrm{~Hz}\right.$, $\delta / \mathrm{ppm}): 189.5,156.1,146.3,135.9,128.3,125.5,119.2$, $79.3,71.3,69.8,69.0,35.1,31.2$.

1-(2-Oxo-2-(pyridin-2-yl)ethyl)pyridinium iodide (L2): A warm $\left(80^{\circ} \mathrm{C}\right)$ red-brown solution of iodine ( $5.06 \mathrm{~g}, 20 \mathrm{mmol}$ ) in $30 \mathrm{~mL}$ of dry pyridine was added to 2-acetylpyridine $(2.42 \mathrm{~g}, 20 \mathrm{mmol})$ under nitrogen. The reaction mixture was stirred at $120^{\circ} \mathrm{C}$ for $30 \mathrm{~min}$. A black solid was observed after being cooled down to room temperature. The precipitate was filtered and washed with dry pyridine $(75 \mathrm{~mL})$. Product L2 $(29.21 \mathrm{~g}, 56 \%)$ was obtained as a yellow-green solid. ${ }^{1} \mathrm{H}$ NMR (DMSO- $\mathrm{d}_{6}$, $400 \mathrm{~Hz}, \delta / \mathrm{ppm}$ ): 9.03-9.01 (m, Py-H, 2H), 8.89-8.86 (m, Py-H, $1 \mathrm{H}), 8.77-8.71(\mathrm{~m}, 1 \mathrm{H}), 8.31-8.26(\mathrm{~m}, \mathrm{Py}-\mathrm{H}, 2 \mathrm{H})$, 8.17-8.12 (m, Py-H, 1H), 8.09-8.06 (m, Рy-H, 1H), 7.86$7.82(\mathrm{~m}, \mathrm{Py}-\mathrm{H}, 1 \mathrm{H}), 6.52\left(\mathrm{~s},-\mathrm{CH}_{2}-, 2 \mathrm{H}\right) .{ }^{13} \mathrm{C} \mathrm{NMR}$ $\left(\right.$ DMSO-d $\left._{6}, 100 \mathrm{~Hz}, \delta / \mathrm{ppm}\right): 191.4,150.4,149.5,146.3$, 146.2, 138.1, 129.1, 127.7, 122.0, 66.6.

L: To a $50 \mathrm{~mL}$ ethanol solution of $\mathbf{L 1}(0.74 \mathrm{~g}, 2 \mathrm{mmol})$ and $\mathbf{L 2}(0.65 \mathrm{~g}, 2 \mathrm{mmol})$, anhydrous ammonium acetate $(1.23 \mathrm{~g}, 16 \mathrm{mmol})$ was added. The mixture was refluxed for $3 \mathrm{~h}$ and then cooled down to room temperature. The precipitate was filtered off and washed with water and ethanol. The mixture was purified by a silica gel column with the eluent of a $\mathrm{CH}_{2} \mathrm{Cl}_{2} /$ hexane mixture $(v / v=1 / 1)$ to give $\mathbf{L}$ as a bright yellow solid $(0.43 \mathrm{~g}, 45 \%) .{ }^{1} \mathrm{H}$ NMR
$\left(\mathrm{CDCl}_{3}, 400 \mathrm{~Hz}, \delta / \mathrm{ppm}\right): 8.73(\mathrm{~d}, J=4.8 \mathrm{~Hz}, 1 \mathrm{H}), 8.67(\mathrm{~d}$, $J=8 \mathrm{~Hz}, 1 \mathrm{H}), 8.42(\mathrm{~d}, J=1.6 \mathrm{~Hz}, 1 \mathrm{H}), 8.11(\mathrm{~d}, J=8.8 \mathrm{~Hz}$, $2 \mathrm{H}), 7.85(\mathrm{t}, J=8 \mathrm{~Hz}, 1 \mathrm{H}), 7.80(\mathrm{~d}, J=1.2 \mathrm{~Hz}, 1 \mathrm{H}), 7.57$ $(\mathrm{d}, J=8.8 \mathrm{~Hz}, 1 \mathrm{H}), 7.35-7.32(\mathrm{~m}, 1 \mathrm{H}), 4.93(\mathrm{t}, J=2 \mathrm{~Hz}$, $2 \mathrm{H}), 4.46(\mathrm{t}, J=2 \mathrm{~Hz}, 2 \mathrm{H}), 4.08(\mathrm{~s}, 5 \mathrm{H}), 1.40(\mathrm{~s}, 9 \mathrm{H}) .{ }^{13} \mathrm{C}$ $\mathrm{NMR}\left(\mathrm{CDCl}_{3}, 100 \mathrm{~Hz}, \delta / \mathrm{ppm}\right): 156.6,155.6,152.2,150.2$, $149.0,137.0,136.8,126.8,125.7,123.7,121.6,117.2,115.9$, 81.8, 70.1, 70.0, 67.2, 34.8, 31.4.

2: The tridentate ligand $\mathbf{L}(0.37 \mathrm{~g}, 0.78 \mathrm{mmol})$ and $\mathrm{K}_{2} \mathrm{PtCl}_{4}(0.36 \mathrm{~g}, 0.86 \mathrm{mmol})$ were dissolved in a mixture of acetonitrile/water $(9 \mathrm{~mL}, v / v=2 / 1)$. The mixture was refluxed for $24 \mathrm{~h}$ and an orange precipitate was formed. The precipitate was centrifuged and successively washed with water, acetonitrile and diethyl ether. The product was recrystallized from a $\mathrm{MeCN} / \mathrm{Et}_{2} \mathrm{O}$ solution mixture to give pure $2(0.4 \mathrm{~g}, 73 \%) .{ }^{1} \mathrm{H}$ NMR $\left(\mathrm{CDCl}_{3}, 400 \mathrm{~Hz}, \delta /\right.$ ppm): $8.94(\mathrm{~d}, J=4.8 \mathrm{~Hz}, 1 \mathrm{H}), 7.96-7.90(\mathrm{~m}, 2 \mathrm{H}), 7.76(\mathrm{~s}$, $1 \mathrm{H}), 7.46(\mathrm{t}, J=6.4 \mathrm{~Hz}, 1 \mathrm{H}), 7.36(\mathrm{~s}, 1 \mathrm{H}), 7.27(\mathrm{~s}, 1 \mathrm{H})$, $7.19(\mathrm{~d}, J=7.6 \mathrm{~Hz}, 1 \mathrm{H}), 7.09(\mathrm{~d}, J=8 \mathrm{~Hz}, 1 \mathrm{H}), 4.76(\mathrm{~s}$, $2 \mathrm{H}), 4.52(\mathrm{~s}, 2 \mathrm{H}), 4.06$ (s, 5H), 1.37 (s, 9H). ${ }^{13} \mathrm{C}$ NMR $\left(\mathrm{CDCl}_{3}, 100 \mathrm{~Hz}, \delta / \mathrm{ppm}\right): 165.5,157.0,154.2,153.5,152.3$, $148.7,143.8,138.9,127.0,123.8,122.5,121.1,114.0,113.9$, $79.9,71.3,70.3,67.4,35.2,31.4 . T_{\text {onset }}=385^{\circ} \mathrm{C}$ (heating

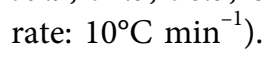

Ethyl-3,4,5-tris(octyloxy)benzoate (D1): Methyl-3,4,5trihydroxybenzoate $(3.68 \mathrm{~g}, 0.02 \mathrm{~mol}), 1$-bromooctane $(10.5 \mathrm{~mL}, 0.06 \mathrm{~mol})$ and $\mathrm{K}_{2} \mathrm{CO}_{3}(16.56 \mathrm{~g}, 0.12 \mathrm{~mol})$ were added to a round-bottomed flask with $100 \mathrm{~mL}$ of dimethylformamide (DMF). The mixture was stirred for $24 \mathrm{~h}$ at $75^{\circ} \mathrm{C}$. The mixture was then poured into $150 \mathrm{~mL}$ of water and extracted with EtOAc for three times. The combined organic extracts were washed with saturated $\mathrm{NaCl}$ solution, dried over anhydrous $\mathrm{Na}_{2} \mathrm{SO}_{4}$, filtered and concentrated under reduced pressure. The residue was purified on a silica gel column eluting with a $\mathrm{CH}_{2} \mathrm{Cl}_{2} /$ hexane mixture $(v / v=1 / 4)$ mixture to give $9.37 \mathrm{~g}(90 \%)$ of a colorless oil of D1. ${ }^{1} \mathrm{H} \mathrm{NMR}\left(\mathrm{CDCl}_{3}, 400 \mathrm{~Hz}, \delta / \mathrm{ppm}\right)$ : 7.25 (s, 2H), 4.04-4.00 (m, 6H), 3.89 (s, 3H), 1.85-1.71 (m, 6H), 1.51-1.43 (m, 6H), 1.33-1.29 (m, 24H), $0.88(\mathrm{t}, J$ $=6.8 \mathrm{~Hz}, 9 \mathrm{H}) ;{ }^{13} \mathrm{C} \mathrm{NMR}\left(\mathrm{CDCl}_{3}, 100 \mathrm{~Hz}, \delta / \mathrm{ppm}\right): 153.2$, $137.4,136.2,105.2,73.4,69.0,68.0,65.5,31.8,31.6,30.3$, 29.4, 25.8, 25.6, 22.7, 22.6, 14.1, 14.0.

3,4,5-Tris(dodecyloxy)benzyl alcohol (D2): To a solution of ethyl-3,4,5-tris(octyloxy)benzoate (10.5 g, $0.02 \mathrm{~mol}$ ) in tetrahydrofuran (THF) was added $\mathrm{LiAlH}_{4}$ $(1.9 \mathrm{~g}, 0.05 \mathrm{~mol})$ slowly at $0^{\circ} \mathrm{C}$. The mixture was stirred at $80^{\circ} \mathrm{C}$ for $10 \mathrm{~h}$ and was then quenched by slow addition of isopropyl alcohol $(3 \mathrm{~mL})$, water $(10 \mathrm{~mL})$ and $30 \%$ aq. $\mathrm{NaOH}(2 \mathrm{~mL})$ successively. The mixture was extracted with EtOAc for three times and the combined organic 
extract was dried by anhydrous $\mathrm{Na}_{2} \mathrm{SO}_{4}$. After the removal of solvent under reduced pressure, the crude product was obtained and further recrystallized from EtOAc to give pure D2 as a colorless oil $(8.4 \mathrm{~g}, 85 \%) .{ }^{1} \mathrm{H}$ NMR $\left(\mathrm{CDCl}_{3}, 400 \mathrm{~Hz}, \delta / \mathrm{ppm}\right): 6.54(\mathrm{~s}, 2 \mathrm{H}), 4.59(\mathrm{~d}, 2 \mathrm{H})$, $3.97(\mathrm{t}, 4 \mathrm{H}, J=7.0 \mathrm{~Hz}), 3.94(\mathrm{t}, 2 \mathrm{H}, J=6.8 \mathrm{~Hz}), 1.84-1.71$ (m, 6H), 1.50-1.42 (m, 6H), 1.31-1.28 (m, 24H), $0.88(\mathrm{t}$, $J=6.8 \mathrm{~Hz}, 9 \mathrm{H}) ;{ }^{13} \mathrm{C} \mathrm{NMR}\left(\mathrm{CDCl}_{3}, 100 \mathrm{~Hz}, \delta / \mathrm{ppm}\right): 153.2$, $138.3,132.3,107.0,73.4,69.1,68.0,47.0,31.8,31.6,30.3$, 29.3, 25.8, 25.6, 22.7, 22.6, 14.1, 14.0.

5-(((4-Iodobenzyl)oxy)methyl)-1,2,3-tris(octyloxy) benzene (D3): To a solution of 3,4,5-tris(dodecyloxy) benzyl alcohol $(2.84 \mathrm{~g}, 5.6 \mathrm{mmol})$ in $20 \mathrm{~mL}$ of THF was added $\mathrm{NaH}(60 \%$ in mineral oil, $0.27 \mathrm{~g}, 6.7 \mathrm{mmol})$ at $0^{\circ} \mathrm{C}$. After the mixture was stirred for $1 \mathrm{~h}$, a solution of p-bromomethyl iodobenzene $(1.84 \mathrm{~g}, 6.2 \mathrm{mmol})$ was dropwisely added and the mixture was further stirred at $60^{\circ} \mathrm{C}$ for $4 \mathrm{~h}$. The solvent was reduced in volume and the mixture was extracted with $\mathrm{CH}_{2} \mathrm{Cl}_{2}$ for three times. The crude product was obtained from the organic extracts and purified on a silica gel with an eluent of a $\mathrm{CH}_{2} \mathrm{Cl}_{2} /$ hexane $(v / v=1 / 3)$ solution mixture to give the entitled colorless oily compound $(3.29 \mathrm{~g}, 83 \%) .{ }^{1} \mathrm{H}$ NMR $\left(\mathrm{CDCl}_{3}, 400 \mathrm{~Hz}\right.$, $\delta / \mathrm{ppm}): 7.68(\mathrm{~d}, J=8 \mathrm{~Hz}, 2 \mathrm{H}), 7.10(\mathrm{~d}, J=8.4 \mathrm{~Hz}, 2 \mathrm{H})$, $6.52(\mathrm{~s}, 2 \mathrm{H}), 4.47(\mathrm{~s}, 2 \mathrm{H}), 4.43(\mathrm{~s}, 2 \mathrm{H}), 3.97-3.92(\mathrm{~m}, 6 \mathrm{H})$, $1.82-1.70(\mathrm{~m}, 6 \mathrm{H}), 1.48-1.43(\mathrm{~m}, 6 \mathrm{H}), 1.36-1.27(\mathrm{~m}$, $24 \mathrm{H}), 0.88(\mathrm{t}, J=7.2 \mathrm{~Hz}, 9 \mathrm{H}) ;{ }^{13} \mathrm{C} \mathrm{NMR}\left(\mathrm{CDCl}_{3}, 100 \mathrm{~Hz}\right.$, $\delta / \mathrm{ppm}): 153.2,138.0,137.8,137.5,133.0,129.7,106.3$, 93.0, 73.4, 72.5, 71.3, 69.2, 31.9, 31.8, 31.6, 30.3, 29.6, 29.4, 29.4, 29.3, 26.1, 22.7, 22.7, 14.1.

Trimethyl((4-(((3,4,5-tris(octyloxy)benzyl)oxy)methyl) phenyl)ethynyl)silane (D4): To a mixture of D3 (2.43 g, $3.4 \mathrm{mmol})$ in triethylamine $(15 \mathrm{~mL})$ and dichloromethane $(15 \mathrm{~mL})$ solution was added $\mathrm{CuI}(150 \mathrm{mg})$ and $\mathrm{Pd}\left(\mathrm{PPh}_{3}\right)_{4}$ $(200 \mathrm{mg})$. Trimethylsilylacetylene $(1 \mathrm{~mL})$ was then added and the suspension was stirred at $75^{\circ} \mathrm{C}$ for $12 \mathrm{~h}$ before being warmed to room temperature. The solvent mixture was evaporated and the crude product was purified by column chromatography on silica gel with $\mathrm{CH}_{2} \mathrm{Cl}_{2}$ /hexane $(v / v=1 / 3)$ solution mixture as the eluent to provide the product as a colorless oil $(1.96 \mathrm{~g}, 85 \%) .{ }^{1} \mathrm{H}$ NMR $\left(\mathrm{CDCl}_{3}, \mathrm{TMS}, \delta, \mathrm{ppm}\right): 7.45(\mathrm{~d}, J=8 \mathrm{~Hz}, 2 \mathrm{H}), 7.29(\mathrm{~d}, J=$ $8.4 \mathrm{~Hz}, 2 \mathrm{H}), 6.53(\mathrm{~s}, 2 \mathrm{H}), 4.52(\mathrm{~s}, 2 \mathrm{H}), 4.43(\mathrm{~s}, 2 \mathrm{H}), 3.97-$ $3.92(\mathrm{~m}, 6 \mathrm{H}), 1.82-1.70(\mathrm{~m}, 6 \mathrm{H}), 1.48-1.41(\mathrm{~m}, 6 \mathrm{H}), 1.32-$ $1.26(\mathrm{~m}, 24 \mathrm{H}), 0.88(\mathrm{t}, J=6.8 \mathrm{~Hz}, 9 \mathrm{H}) .{ }^{13} \mathrm{C} \mathrm{NMR}\left(\mathrm{CDCl}_{3}\right.$, $100 \mathrm{~Hz}, \delta, \mathrm{ppm}): 153.0,138.7,137.5,132.8,132.2,127.6$, $121.4,106.4,83.5,73.4,72.6,71.5,69.2,31.9,31.8,31.6$, $30.3,29.4,29.4,29.3,26.1,22.7,22.6,14.1,0.0$.

5-((4-Ethynylbenzyl)oxy)methyl)-1,2,3-tris(octyloxy) benzene (D): To a solution of $\mathbf{D} 4(1.7 \mathrm{~g}, 2.5 \mathrm{mmol})$ in
$\mathrm{MeOH}(15 \mathrm{~mL})$ and $\mathrm{CH}_{2} \mathrm{Cl}_{2}(15 \mathrm{ml})$ solution, $\mathrm{K}_{2} \mathrm{CO}_{3}$ $(0.7 \mathrm{~g}, 5 \mathrm{mmol})$ was added. The mixture was stirred vigorously at room temperature for $10 \mathrm{~h}$ and was then concentrated and extracted with $\mathrm{CH}_{2} \mathrm{Cl}_{2}$ for three times. The combined organic extract was collected and dried. The crude product was purified by column chromatography on silica gel with $\mathrm{CH}_{2} \mathrm{Cl}_{2} /$ hexane $(v / v=1 / 3)$ solution mixture as the eluent to provide the target compound as a colorless oil (1.44 g, 95\%). ${ }^{1} \mathrm{H}$ NMR $\left(\mathrm{CDCl}_{3}, \mathrm{TMS}, \delta, \mathrm{ppm}\right): 7.48(\mathrm{~d}, J=8.4 \mathrm{~Hz}, 2 \mathrm{H}), 7.32(\mathrm{~d}, J$ $=8.4 \mathrm{~Hz}, 2 \mathrm{H}), 6.53(\mathrm{~s}, 2 \mathrm{H}), 4.53(\mathrm{~s}, 2 \mathrm{H}), 4.45(\mathrm{~s}, 2 \mathrm{H})$, 3.98-3.92 (m, 6H), $3.07(\mathrm{~s}, 1 \mathrm{H}), 1.83-1.70(\mathrm{~m}, 6 \mathrm{H}), 1.48-$ $1.43(\mathrm{~m}, 6 \mathrm{H}), 1.36-1.25(\mathrm{~m}, 24 \mathrm{H}), 0.88(\mathrm{t}, J=6.8 \mathrm{~Hz}, 9 \mathrm{H})$. ${ }^{13} \mathrm{C}$ NMR $\left(\mathrm{CDCl}_{3}, 100 \mathrm{~Hz}, \delta / \mathrm{ppm}\right): 153.2,139.2,137.8$, $133.0,132.2,127.6,121.4,106.4,83.5,73.4,72.6,71.5$, $69.2,31.9,31.8,31.6,30.3,29.4,29.4,29.3,26.1,22.7,22.6$, 14.1

1: To $2(0.38 \mathrm{~g}, 0.54 \mathrm{mmol})$ in a mixture of $\mathrm{CHCl}_{3} /$ $i-\mathrm{Pr}_{2} \mathrm{NH}(v / v=1 / 1)(20 \mathrm{~mL}), \mathbf{D}(0.33 \mathrm{~g}, 0.54 \mathrm{mmol})$ and a catalytic amount of $\mathrm{CuI}(5 \mathrm{mg})$ were added, and the mixture was stirred for $16 \mathrm{~h}$ under nitrogen and monitored by TLC. The solvent was removed in vacuo and the crude product was purified by recrystallization from $\mathrm{CHCl}_{3} / \mathrm{Et}_{2} \mathrm{O}$ with the yield of $83 \%$. ${ }^{1} \mathrm{H}$ NMR $\left(\mathrm{CDCl}_{3}\right.$, TMS, $\delta, \mathrm{ppm}): 9.18(\mathrm{dd}, J=56.4,4.8 \mathrm{~Hz}, 1 \mathrm{H}), 8.14-7.97$ $(\mathrm{m}, 3 \mathrm{H}), 7.58-7.47(\mathrm{~m}, 4 \mathrm{H}), 7.38-7.27(\mathrm{~m}, 3 \mathrm{H}), 7.13(\mathrm{t}, J$ $=8 \mathrm{~Hz}, 2 \mathrm{H}), 6.55(\mathrm{~d}, J=16.4 \mathrm{~Hz}, 2 \mathrm{H}), 4.81(\mathrm{~s}, 2 \mathrm{H}), 4.53$ $(\mathrm{d}, J=6.8 \mathrm{~Hz}, 4 \mathrm{H}), 4.45(\mathrm{~s}, 2 \mathrm{H}), 4.08(\mathrm{~d}, J=8 \mathrm{~Hz}, 5 \mathrm{H})$, 4.00-3.92 (m, 6H), 1.46-1.45 (m, 10H), 1.35-1.25 (m, $26 \mathrm{H}), 0.88(\mathrm{t}, J=6.4 \mathrm{~Hz}, 9 \mathrm{H})$. IR $\left(\mathrm{KBr}, \mathrm{cm}^{-1}\right): 2,095$ $(-\mathrm{C} \equiv \mathrm{C}-) ; T_{\text {onset }}=331^{\circ} \mathrm{C}$ (heating rate: $10^{\circ} \mathrm{C} \mathrm{min}^{-1}$ ).

\section{Preparation and characterization of FePt nanoparticles}

The bimetallic complexes $\mathbf{1}$ and $\mathbf{2}$ were used as singlesource precursors to prepare FePt NPs. The precursor was first put in a ceramic boat and the boat was then placed in a tube furnace equipped with temperature and gas-flow controls. The precursor was heated to $800^{\circ} \mathrm{C}$ at the rate of $15^{\circ} \mathrm{C} \min ^{-1}$ and kept for $1 \mathrm{~h}$ at $800^{\circ} \mathrm{C}$ under an $\mathrm{Ar} / \mathrm{H}_{2}$ atmosphere. After being cooled to room temperature, black powdery FePt NPs were formed. FePt-1 and FePt-2 NPs were synthesized from 1 and 2, respectively. The resultant nanomaterials were then characterized by PXRD, TEM, EDX and PPMS.

\section{Patterning of the precursors by NIL}

A solution of 1 in chloroform $\left(20 \mathrm{mg} \mathrm{mL}^{-1}\right)$ was prepared and filtered by a syringe with a $0.22 \mu \mathrm{m}$ pore size hydrophobic Nylon membrane. $20 \mu \mathrm{L}$ of the solution was drop-casted onto a Si wafer $\left(10 \times 10 \mathrm{~mm}^{2}\right)$, which was 


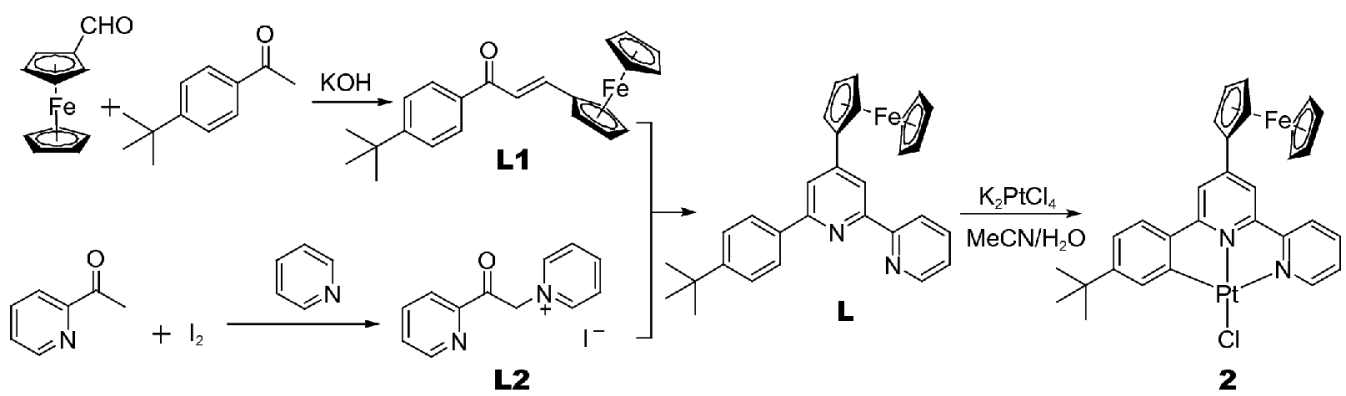

Scheme 1 Synthetic scheme of $\mathrm{Fc}\left(\mathrm{C}^{\wedge} \mathrm{N}^{\wedge} \mathrm{N}\right) \mathrm{PtCl}(2)$ with a tridentate coplanar structure.

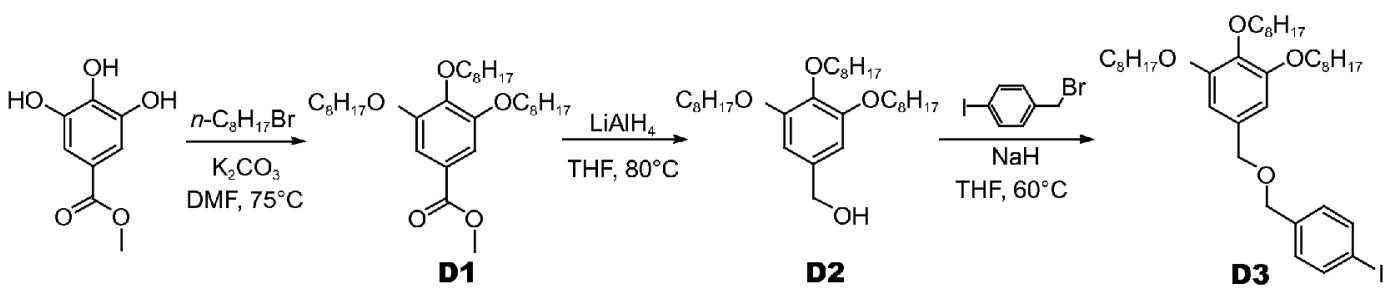

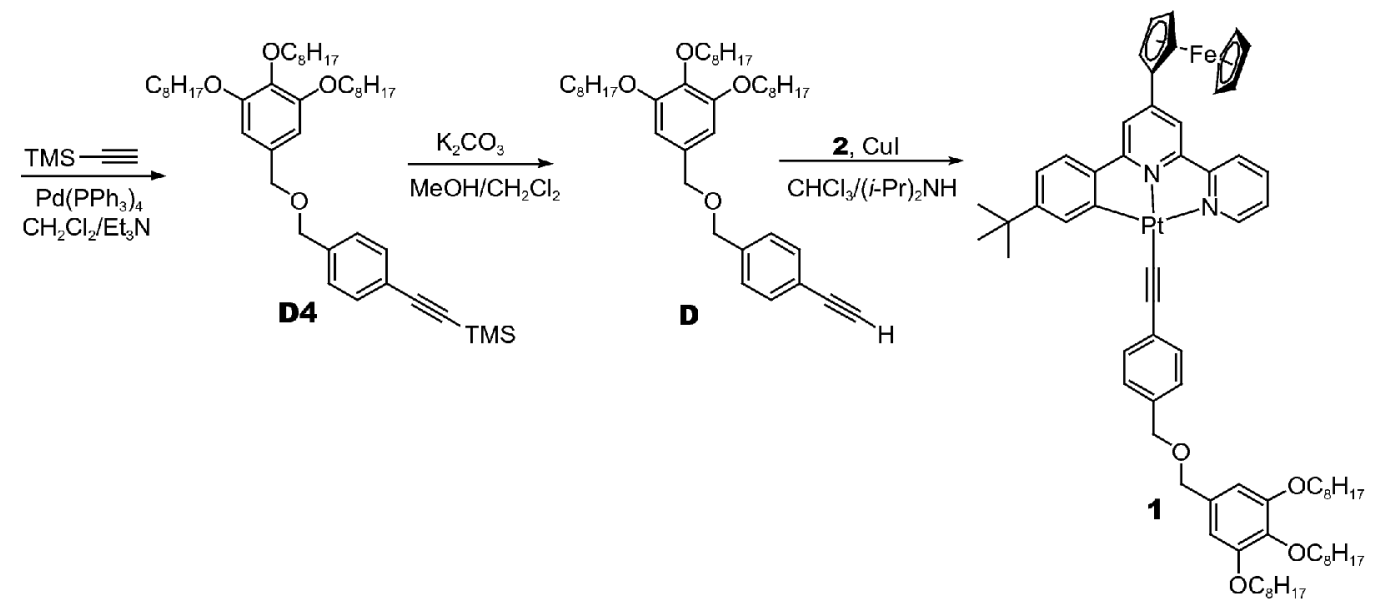

Scheme 2 Synthetic routes to Fe,Pt-containing complex 1 with a flexible dendritic tail.

previously cleaned with acetone. Then, a polydimethylsiloxane (PDMS) template with special stamps such as line, hole or pillar arrays was immediately imprinted onto the wafer for $5 \mathrm{~min}$ under $1 \mathrm{~N} \mathrm{~cm}^{-2}$ of pressure. After removing the template, the reverse stamps of the precursor $\mathbf{1}$ were left on the $\mathrm{Si}$ substrate. The substrate was annealed to get the ferromagnetic patterns according to the same pyrolysis condition as for the preparation of FePt NPs.

\section{RESULTS AND DISCUSSION}

\section{Neutral Fe,Pt-containing bimetallic complexes with $\mathrm{C}^{\wedge} \mathrm{N}^{\wedge} \mathrm{N}$ tridentate ligand}

The synthesis of the ligand precursors and complexes 1-2 are depicted in Schemes 1 and 2. Ferrocenyl-functionalized tridentate ligand $(\mathbf{L})$ with a bipyridine moiety and a modified phenyl group was firstly prepared based on the Kröhnke methodology via an isolated enone (Scheme 1). The ligand $\mathbf{L}$ was then easily coordinated with $\mathrm{K}_{2} \mathrm{PtCl}_{4}$ to give the bimetallic coplanar compound 2, in which the platinum center binds to three adjacent moieties to form a conjugated plane. The coordinated chloride in $\mathbf{2}$ can be easily substituted by a terminal acetylide ligand, and here a terminal alkyne substituted dendritic ligand $\mathbf{D}$ was used to attach to Pt to give the complex 1 with good solubility in common organic solvents. All the new materials were air-stable and fully characterized by ${ }^{1} \mathrm{H}$ and ${ }^{13} \mathrm{C} \mathrm{NMR}$, infrared and UV-vis spectroscopies. The thermal stabilities of the metallic complexes were also studied by 

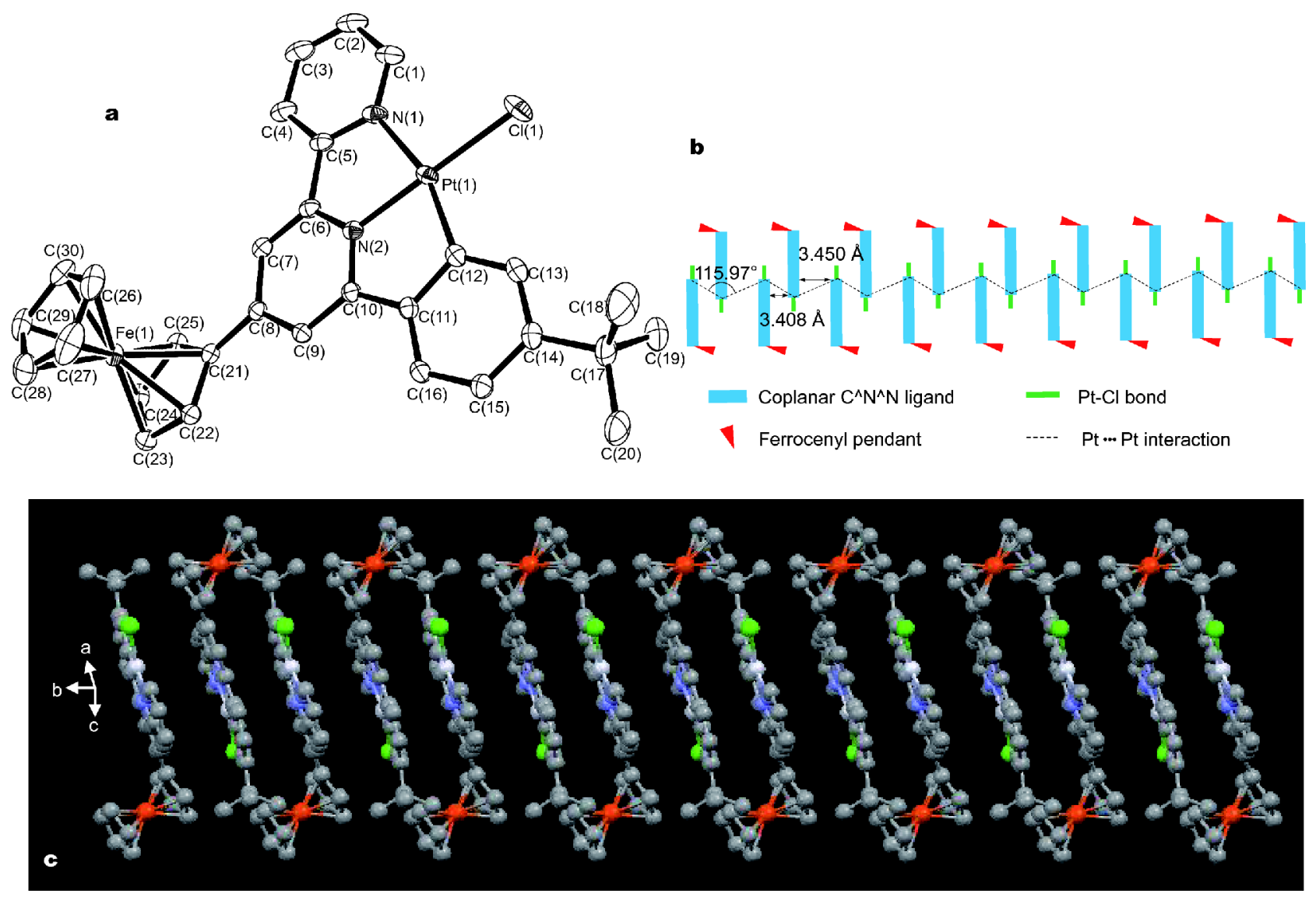

Figure 1 (a) ORTEP views of the bimetallic complex 2 and the partial atom numbering scheme. The H-atoms are not shown for clarity. (b) Schematic representation of the stacking orientations of $\mathbf{2}$ (blue and green colors represent sets of ligands on the molecule and dotted lines represent Pt...Pt interactions). (c) Illustrations of the $\pi-\pi$ stacking and Pt...Pt interactions in the molecular structure of 2 along $b$-axis.

thermogravimetric analysis (TGA), in which the complex 1 with flexible dendritic tails showed a lower onset decomposition temperature $\left(330^{\circ} \mathrm{C}\right)$ than 2 . Their thermograms are demonstrated in Fig. S1.

The molecular structure of complex $\mathbf{2}$ in the solid state was established by X-ray crystallography and is shown in Fig. 1a. The metric parameters are given in the supporting information and the selected bond distances and angles are listed in Table 1. The crystals were grown by slow vapour diffusion of $\mathrm{Et}_{2} \mathrm{O}$ into a chloroform solution of $\mathbf{2}$. The structure revealed that the Pt ion binds tightly to the three adjacent coplanar sites and an irregular squareplanar motif was formed. A linear chain-like packing between molecules was observed with the Pt...Pt bonds that stacked on top of each other in a head-to-tail fashion, while the ferrocenyl groups in the two adjacent molecules were arranged in the opposite directions. The torsion angle of Pt...Pt...Pt is $115.97^{\circ}$, and the distances of the stacking plane are measured to be alternate between 3.408
Table 1 Selected bond lengths $(\AA)$ and angles $\left(^{\circ}\right)$ for $\mathbf{2}$

\begin{tabular}{cccc}
\hline \multicolumn{3}{c}{ Length } & Angle \\
\hline $\mathrm{Pt}(1)-\mathrm{N}(1)$ & $2.1075(16)$ & $\mathrm{N}(2)-\mathrm{Pt}(1)-\mathrm{C}(12)$ & $82.33(6)$ \\
$\mathrm{Pt}(1)-\mathrm{N}(2)$ & $1.9491(15)$ & $\mathrm{N}(2)-\mathrm{Pt}(1)-\mathrm{N}(1)$ & $79.49(6)$ \\
$\mathrm{Pt}(1)-\mathrm{C}(12)$ & $1.9873(18)$ & $\mathrm{C}(12)-\mathrm{Pt}(1)-\mathrm{N}(1)$ & $161.71(6)$ \\
$\mathrm{Pt}(1)-\mathrm{Cl}(1)$ & $2.3089(9)$ & $\mathrm{N}(2)-\mathrm{Pt}(1)-\mathrm{Cl}(1)$ & $177.14(4)$ \\
& & $\mathrm{C}(12)-\mathrm{Pt}(1)-\mathrm{Cl}(1)$ & $98.90(5)$ \\
& & $\mathrm{N}(1)-\mathrm{Pt}(1)-\mathrm{Cl}(1)$ & $99.17(5)$ \\
\hline
\end{tabular}

and $3.450 \AA$. In addition, their absorption spectra were recorded in solution phase (Fig. S2). The broad peak from the ferrocenyl group was obviously shifted from $460 \mathrm{~nm}$ to $520 \mathrm{~nm}$ after coordination with the metal center, and the shoulder peak at $375 \mathrm{~nm}$ appeared owing to the intermolecular metal-to-ligand charge transfer (MLCT) and intraligand transitions $[38,39]$. 

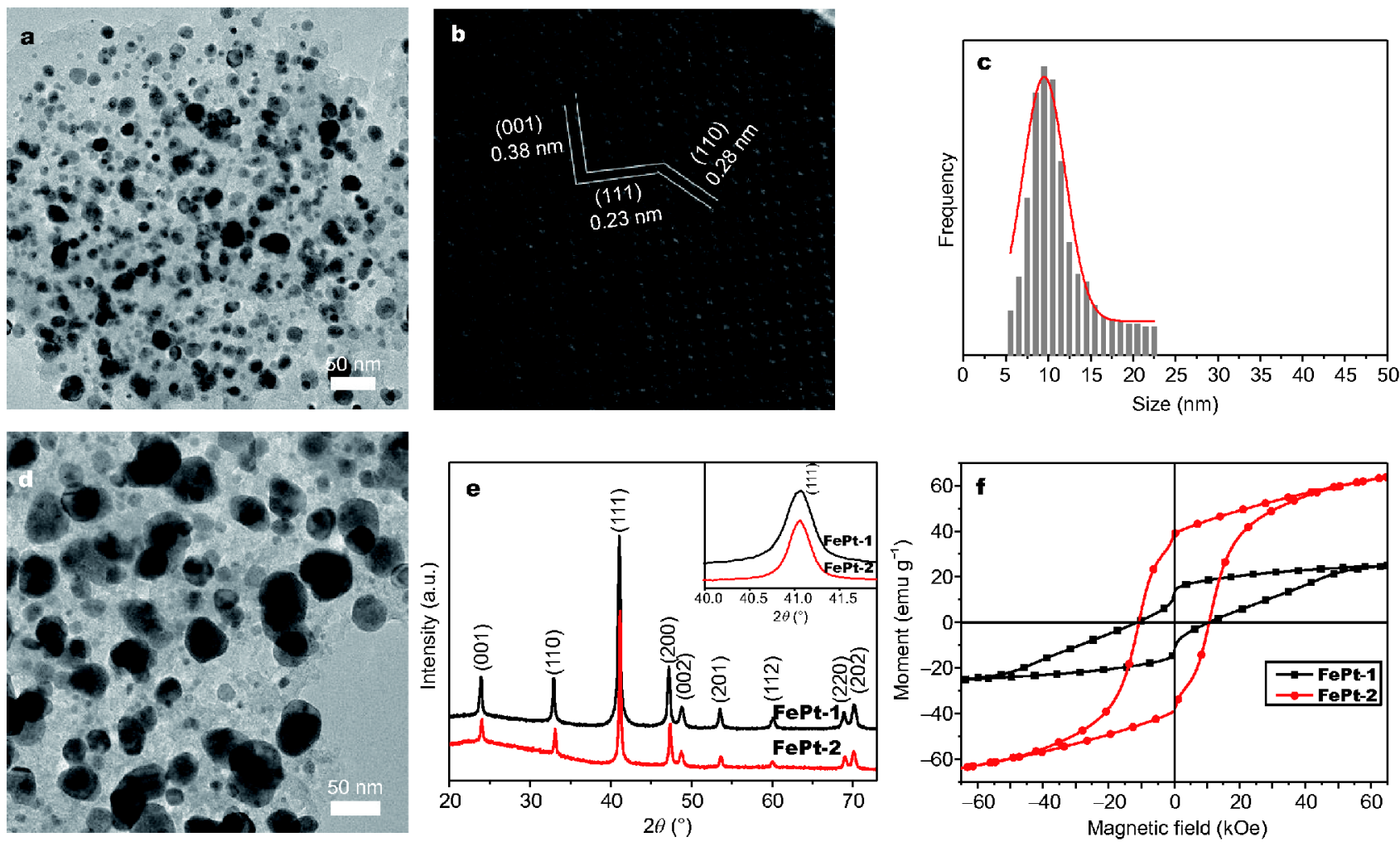

Figure 2 (a) and (d): TEM images of the as-synthesized FePt-1 NPs and FePt-2 NPs, respectively; (b) high-resolution TEM image of FePt-1 NPs with lattice fringe; (c) size distribution of FePt-1 NPs; (e) powder XRD of the resultant FePt-1 and FePt-2 NPs. (Inset: the amplified (111) peak in XRD pattern); (f) magnetic loops of the FePt-1 NPs and FePt-2 NPs measured at room temperature.

\section{Preparation and characterization of FePt NPs}

Two bimetallic complexes 1 and $\mathbf{2}$ acting as single-source precursors were pyrolyzed to synthesize FePt NPs under a protective gas environment $\left(95 \% \mathrm{Ar}+5 \% \mathrm{H}_{2}\right)$. The introduction of $5 \%$ hydrogen was identified to protect the NPs from potential trace oxidation and was also revealed to better control the morphology of the final products by hydrogen adsorption on the surface of the seeds [40,41]. The precursor was placed in a quartz boat which was put into a tube furnace that was full of a given gas, and then it was heated to $800^{\circ} \mathrm{C}$ at the heating rate of $15^{\circ} \mathrm{C} \mathrm{min}$ and held for $1 \mathrm{~h}$ at $800^{\circ} \mathrm{C}$. After being cooled down to ambient temperature, FePt-1 NPs and FePt-2 NPs were generated from 1 and 2, respectively.

The morphology and size of the resultant FePt NPs were investigated by typical TEM and the corresponding images are displayed in Fig. 2. The resultant FePt NPs were spherical in shape and were dispersed on the carbonaceous matrix, which could protect the NPs from oxidation in an ambient environment. The size distributions of the obtained FePt-1 NPs and FePt-2 NPs were narrow, and an obvious discrepancy in size was easily observed. The FePt-1 NPs had an average size of $9.5 \mathrm{~nm}$ with a standard deviation of 2.5 according to the statistical analysis (Fig. 2c) from the TEM image (Fig. 2a), while the average size of FePt-2 NPs was larger than $20 \mathrm{~nm}$ and the size distribution was also very broad as shown in Fig. S3. As the spatial structures of the organometallic precursors would affect the size, morphology or phase of the NPs [27,42], the incorporation of the dendritic functional group in $\mathbf{1}$ would destruct or weaken the $\pi$-conjugated coplanar stacking and Pt...Pt interactions in comparison to that of $\mathbf{2}$, which is consistent with the UV-vis spectral results. Hence, the growth of FePt-2 NPs was easier with larger size than that of FePt-1 NPs due to the stronger interactions. Furthermore, lattice fringes with the distance of $0.38,0.27,0.23 \mathrm{~nm}$ were measured by the high-resolution TEM image (Fig. 2b), which corresponded to the (001), (110), (111) planes of FePt alloy NPs, respectively. Besides, the compositions of the NPs were characterized by EDX, in which both of the FePt-1 and FePt-2 NPs were found to have nearly equal atomic ratio of $\mathrm{Fe}$ to $\mathrm{Pt}$, which were consistent with the stoichiometric ratio of the precursors. 

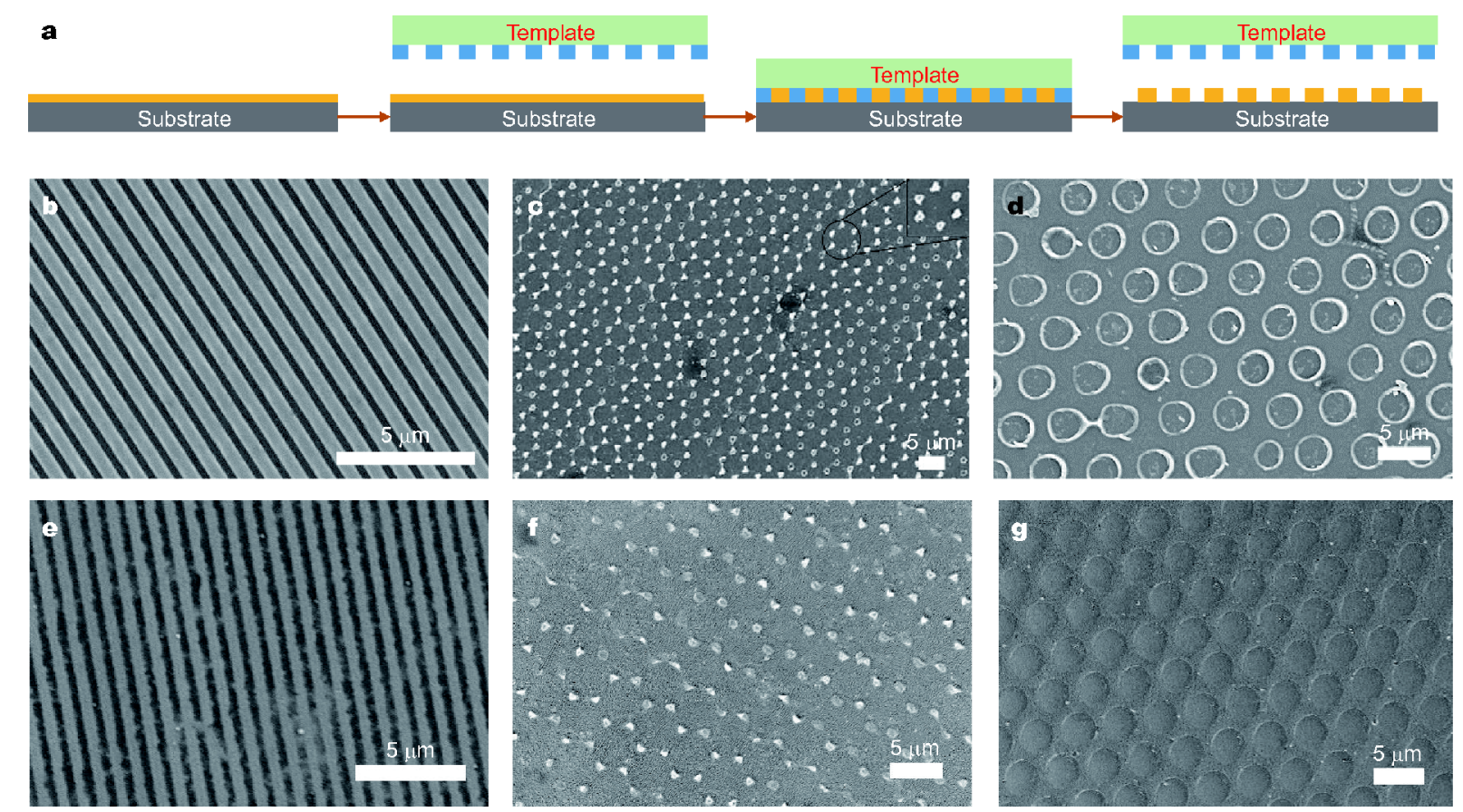

Figure 3 (a) Schematic illustration of the lithographic process; (b-d): SEM images of the line, hexagonal pillar and hole arrays ordered patterns of the organometallic precursor 1, respectively; (e-g): the SEM images of the line, hexagonal pillar and hole arrays magnetic patterns after pyrolysis corresponding to $(b-d)$, respectively.

The crystallinity and phase purity of the as-prepared FePt NPs were confirmed by PXRD studies. The XRD patterns shown in Fig. 2e matched well with the standard FePt alloy NPs (JCPDS No 43-1359). The appearance of the peaks (001), (110) and the emergence of the diffraction of the peaks $(200) /(002)$ and $(220) /(202)$, all of the characteristics indicated that the formed FePt NPs had a chemically ordered fct crystalline structure. The (111) peak at $41.06^{\circ}$ indicated the atomic ratio of $\mathrm{Fe} / \mathrm{Pt}$, as estimated by the Klemmer's report [43], and it was about 53:47 [44]. The full width at half maximum of the (111) peak for FePt-2 NPs was narrower than that for FePt-1 NPs due to the difference in particle size. The average size of $9.7 \mathrm{~nm}$ for FePt-1 NPs was also calculated by the Scherrer formula on the basis of the (111) peak, while the size for FePt-2 NPs was $20.5 \mathrm{~nm}$, which are in good agreement with the TEM analysis.

The magnetization curves of the as-synthesized FePt NPs at room temperature are shown in Fig. 2f. The saturated moment at the applied magnetic field up to $6.5 \mathrm{~T}$ of FePt-2 NPs $\left(63.7 \mathrm{emu} \mathrm{g}^{-1}\right)$ was larger than that of FePt-1 NPs $\left(25.3 \mathrm{emu} \mathrm{g}^{-1}\right)$ due to the different carbon content in their respective precursors, which is relatively lower than that of the reported FePt NPs, because the assynthesized FePt nanomaterials from the pyrolysis of organometallic precursors contain a certain amount of amorphous carbon. Nevertheless, the hysteresis loops of FePt-1 and FePt-2 NPs gave a similar coercivity of $10.6 \mathrm{kOe}$. Therefore, the chemical structures of the bimetallic precursors play an important role in the size distinction of the formed FePt NPs, but with negligible effect on their coercivities. The mass of carbon was taken into account in the calculation of magnetic moment (emu g ${ }^{-1}$ ) except that of FePt NPs, which indicated that the part of carbon with no contribution on magnetic moment contributed to the sharp decrease of the bulk value of the saturation magnetization of FePt NPs. In addition, the magnetic fluctuations in the hysteresis loop of FePt-1 NPs could be ascribed to the existence of amorphous carbon.

\section{Patterning of organometallic precursor by NIL}

The storage layer in magnetic data recording media is composed of ferromagnetic NPs to allow writing and storing magnetic transitions at high densities. Especially in BPM, each recording bit contains hundreds of NPs with ultra-high coercivity. The strategies of making the required patterns on selective substrate were developed rapidly in the past decades, and a high-throughput technique of NIL was applied here for patterning of the 
FePt NPs. Due to the strong Pt $\cdots$ Pt interactions and $\pi-\pi$ stacking behavior in the precursor, the FePt-2 NPs easily grew into alloy with bigger size, but the flexible dendritic tails in the hemiphasmidic complex 1 reduce the stacking behavior and enhance the processability. The precursor 1 was used for patterning by NIL and this is the first time to get the ordered patterns by using small molecular organometallic complex. The procedures are given in the schematic illustration in Fig. 3a. The organometallic precursors 1 and 2 were first dissolved in $\mathrm{CHCl}_{3}$ to get saturated solutions, in which the gel-like solution of the functionalized compound $\mathbf{1}$ exhibited better solution processibility and was successfully patterned on silicon substrate by NIL with a soft PDMS template. Fig. 3b-d show the ordered patterns of $\mathbf{1}$ with line, hexagonal pillar and hole arrays morphology, respectively. The obtained arrays perfectly match with the opposite shape of the corresponding templates. After pyrolysis by using the same conditions as for the preparation of FePt-1 NPs preparation, the morphologies are well-preserved with the pre-defined periodicity, except for the decrease in the height of the patterns due to the collapse of the organic molecular frameworks, which have been identified by the SEM images with obvious lower contrasts as shown in Fig. $3 \mathrm{e}-\mathrm{g}$. Although the size of pattern still needs to be further narrowed down, the potential application for BPM by using a small metal complex has been demonstrated, and the various morphology obtained further identified the feasibility of this technique. The line arrays in this paper were obtained by the DVD-type soft template, which is suitable for common DVD recording media. Besides, we also revealed the universality of NIL by various patterns in different scales.

\section{CONCLUSIONS}

In summary, a neutral chelated complex 2 was synthesized and subsequent functionalized to get compound $\mathbf{1}$ by the $\mathrm{CuI}$-catalyzed dehydrohalogenation reaction. Both $\mathbf{1}$ and $\mathbf{2}$ were applied for the preparation of FePt NPs. The dendritic functional group in $\mathbf{1}$ could effectively tune the spatial property and weaken the molecular interactions, which would further make the size of the as-prepared FePt NPs from 1 smaller than that of 2 . The resultant NPs showed similar coercivities of $10.6 \mathrm{kOe}$, but different magnetic moments were detected due to the distinct discrepancy of the molecular structures of the precursors. Also, the bimetallic compound $\mathbf{1}$ exhibited gel-like property in $\mathrm{CHCl}_{3}$ and its saturated solution was successfully patterned on silicon substrate. The pyrolyzed patterns were found to be perpendicularly magnetic and suitable for future magnetic data recording applications.

Received 6 July 2018; accepted 5 September 2018;

published online 26 September 2018

1 Wang D, Xin HL, Hovden R, et al. Structurally ordered intermetallic platinum-cobalt core-shell nanoparticles with enhanced activity and stability as oxygen reduction electrocatalysts. Nat Mater, 2013, 12: 81-87

2 Li J, Wang G, Wang J, et al. Architecture of PtFe/C catalyst with high activity and durability for oxygen reduction reaction. Nano Res, 2014, 7: 1519-1527

3 Xia T, Liu J, Wang S, et al. Nanomagnetic CoPt truncated octahedrons: facile synthesis, superior electrocatalytic activity and stability for methanol oxidation. Sci China Mater, 2017, 60: 57-67

$4 \mathrm{Li} \mathrm{Q}, \mathrm{Wu} \mathrm{L}, \mathrm{Wu} \mathrm{G}$, et al. New approach to fully ordered fct-FePt nanoparticles for much enhanced electrocatalysis in acid. Nano Lett, 2015, 15: 2468-2473

5 Hong Y, Kim HJ, Yang D, et al. Facile synthesis of fully ordered $\mathrm{L} 1_{0}$-FePt nanoparticles with controlled Pt-shell thicknesses for electrocatalysis. Nano Res, 2017, 10: 2866-2880

6 Dong Q, Li G, Ho CL, et al. A polyferroplatinyne precursor for the rapid fabrication of $\mathrm{L}_{0}$-FePt-type bit patterned media by nanoimprint lithography. Adv Mater, 2012, 24: 1034-1040

7 Meng Z, Li G, Wong HF, et al. Patterning of $\mathrm{L}_{0}$ FePt nanoparticles with ultra-high coercivity for bit-patterned media. Nanoscale, 2017, 9: 731-738

8 Dong Q, Li G, Ho CL, et al. Facile generation of $\mathrm{L}_{0}-\mathrm{FePt}$ nanodot arrays from a nanopatterned metallopolymer blend of iron and platinum homopolymers. Adv Funct Mater, 2014, 24: 857-862

9 Dong Q, Meng Z, Ho CL, et al. A molecular approach to magnetic metallic nanostructures from metallopolymer precursors. Chem Soc Rev, 2018, 47: 4934-4953

10 Lee H, Shin TH, Cheon J, et al. Recent developments in magnetic diagnostic systems. Chem Rev, 2015, 115: 10690-10724

11 Zhu K, Ju Y, Xu J, et al. Magnetic nanomaterials: chemical design, synthesis, and potential applications. Acc Chem Res, 2018, 51: 404-413

$12 \mathrm{Yu} \mathrm{J}$, Gao W, Liu F, et al. Tuning crystal structure and magnetic property of dispersible FePt intermetallic nanoparticles. Sci China Mater, 2018, 61: 961-968

13 Sun S. Recent advances in chemical synthesis, self-assembly, and applications of FePt nanoparticles. Adv Mater, 2006, 18: 393-403

14 Wu L, Mendoza-Garcia A, Li Q, et al. Organic phase syntheses of magnetic nanoparticles and their applications. Chem Rev, 2016, 116: $10473-10512$

15 Sun S, Murray CB, Weller D, et al. Monodisperse FePt nanoparticles and ferromagnetic FePt nanocrystal superlattices. Science, 2000, 287: 1989-1992

16 Hou Y, Kondoh H, Kogure T, et al. Preparation and characterization of monodisperse FePd nanoparticles. Chem Mater, 2004, 16: $5149-5152$

17 Liu F, Zhu J, Yang W, et al. Building nanocomposite magnets by coating a hard magnetic core with a soft magnetic shell. Angew Chem Int Ed, 2014, 53: 2176-2180

18 da Silva TL, Varanda LC. Perpendicularly self-oriented and shapecontrolled $\mathrm{L1}_{0}$-FePt nanorods directly synthesized by a temperature-modulated process. Nano Res, 2011, 4: 666-674

19 Wellons MS, Morris WH, Gai Z, et al. Direct synthesis and size selection of ferromagnetic FePt nanoparticles. Chem Mater, 2007, 


\section{9: $2483-2488$}

20 Capobianchi A, Colapietro M, Fiorani D, et al. General strategy for direct synthesis of $\mathrm{L}_{0}$ nanoparticle alloys from layered precursor: the case of FePt. Chem Mater, 2009, 21: 2007-2009

21 Faustini M, Capobianchi A, Varvaro G, et al. Highly controlled dip-coating deposition of $f c t$ FePt nanoparticles from layered salt precursor into nanostructured thin films: An easy way to tune magnetic and optical properties. Chem Mater, 2012, 24: 1072-1079

22 Kang E, Jung H, Park JG, et al. Block copolymer directed one-pot simple synthesis of $\mathrm{L}_{0}$-phase FePt nanoparticles inside ordered mesoporous aluminosilicate/carbon composites. ACS Nano, 2011, 5: $1018-1025$

23 Lee SR, Yang S, Kim YK, et al. Microstructural evolution and phase transformation characteristics of Zr-doped FePt films. J Appl Phys, 2002, 91: 6857-6859

24 He J, Bian B, Zheng Q, et al. Direct chemical synthesis of well dispersed $\mathrm{L1}_{0}$-FePt nanoparticles with tunable size and coercivity. Green Chem, 2016, 18: 417-422

25 Elkins K, Li D, Poudyal N, et al. Monodisperse face-centred tetragonal FePt nanoparticles with giant coercivity. J Phys D-Appl Phys, 2005, 38: 2306-2309

26 Liu K, Ho CL, Aouba S, et al. Synthesis and lithographic patterning of FePt nanoparticles using a bimetallic metallopolyyne precursor. Angew Chem Int Ed, 2008, 47: 1255-1259

27 Meng Z, Li G, Ng SM, et al. Nanopatterned $\mathrm{L}_{0}$-FePt nanoparticles from single-source metallopolymer precursors for potential application in ferromagnetic bit-patterned media magnetic recording. Polym Chem, 2016, 7: 4467-4475

28 Dong Q, Li G, Wang $\mathrm{H}$, et al. Investigation of pyrolysis temperature in the one-step synthesis of $\mathrm{L}_{0}$ FePt nanoparticles from a FePt-containing metallopolymer. J Mater Chem C, 2015, 3: 734741

29 Dong Q, Qu W, Liang W, et al. Porphyrin-based metallopolymers: synthesis, characterization and pyrolytic study for the generation of magnetic metal nanoparticles. J Mater Chem C, 2016, 4: 50105018

30 Dong Q, Qu W, Liang W, et al. Metallopolymer precursors to $\mathrm{L1}_{0^{-}}$CoPt nanoparticles: synthesis, characterization, nanopatterning and potential application. Nanoscale, 2016, 8: 7068-7074

31 Li GJ, Leung CW, Lei ZQ, et al. Patterning of FePt for magnetic recording. Thin Solid Films, 2011, 519: 8307-8311

32 Xing LB, Yu S, Wang XJ, et al. Reversible multistimuli-responsive vesicles formed by an amphiphilic cationic platinum(II) terpyridyl complex with a ferrocene unit in water. Chem Commun, 2012, 48: 10886-10888

33 Mitra K, Shettar A, Kondaiah P, et al. Biotinylated platinum(II) ferrocenylterpyridine complexes for targeted photoinduced cytotoxicity. Inorg Chem, 2016, 55: 5612-5622

34 Mitra K, Basu U, Khan I, et al. Remarkable anticancer activity of ferrocenyl-terpyridine platinum(II) complexes in visible light with low dark toxicity. Dalton Trans, 2014, 43: 751-763

35 Yoshio M, Mukai T, Ohno H, et al. One-dimensional ion transport in self-organized columnar ionic liquids. J Am Chem Soc, 2004,
126: 994-995

36 Dong F, Guo Y, Xu P, et al. Hydrothermal growth of $\mathrm{MoS}_{2} / \mathrm{Co}_{3} \mathrm{~S}_{4}$ composites as efficient Pt-free counter electrodes for dye-sensitized solar cells. Sci China Mater, 2017, 60: 295-303

$37 \mathrm{Xu} \mathrm{Z}$, Yin $\mathrm{X}$, Guo Y, et al. Ru-doping in $\mathrm{TiO}_{2}$ electron transport layers of planar heterojunction perovskite solar cells for enhanced performance. J Mater Chem C, 2018, 6: 4746-4752

38 Leung SYL, Lam WH, Yam VWW. Dynamic scaffold of chiral binaphthol derivatives with the alkynylplatinum(II) terpyridine moiety. Proc Natl Acad Sci USA, 2013, 110: 7986-7991

39 Leung SYL, Yam VWW. Hierarchical helices of helices directed by $\mathrm{Pt} \ldots \mathrm{Pt}$ and $\pi-\pi$ stacking interactions: reciprocal association of multiple helices of dinuclear alkynylplatinum(II) complex with luminescence enhancement behavior. Chem Sci, 2013, 4: 42284234

$40 \mathrm{Wu}$ J, Hou Y, Gao S. Controlled synthesis and multifunctional properties of FePt-Au heterostructures. Nano Res, 2011, 4: 836848

41 Bian BR, Xia WX, Du J, et al. Effect of $\mathrm{H}_{2}$ on the formation mechanism and magnetic properties of FePt nanocrystals. IEEE Trans Magn, 2013, 49: 3307-3309

42 Bauer JC, Chen X, Liu Q, et al. Converting nanocrystalline metals into alloys and intermetallic compounds for applications in catalysis. J Mater Chem, 2008, 18: 275-282

43 Klemmer TJ, Shukla N, Liu C, et al. Structural studies of $\mathrm{Ll}_{0} \mathrm{FePt}$ nanoparticles. Appl Phys Lett, 2002, 81: 2220-2222

44 Saita S, Maenosono S. FePt nanoparticles with a narrow composition distribution synthesized via pyrolysis of iron(III) ethoxide and platinum(II) acetylacetonate. Chem Mater, 2005, 17: 37053710

Acknowledgements This work was supported by the National Natural Science Foundation of China (21701112, 21504074 and 51573151), Hong Kong Research Grants Council (HKBU12317216, PolyU153062/18P and PolyU153015/14P), Areas of Excellence Scheme, University Grants Committee of HKSAR (AoE/P-03/08), the Hong Kong Polytechnic University (1-ZE1C and 1-ZE25), the Science, Technology and Innovation Committee of Shenzhen Municipality (JCYJ20160531193836532), and Ms Clarea $\mathrm{Au}(847 \mathrm{~S})$ for the Endowed Professorship in Energy.

Author contributions Meng Z, Yu ZQ and Wong WY designed the project; Meng $Z$ did the experiments, analyzed the data and wrote the paper; Wong HF performed the characterization of magnetic hysteresis loops; Zhu N analyzed the crystal structure; Li G, Ho CL and Leung CW analyzed the results and put forward valuable suggestions; Wong WY was also responsible for writing the paper. All authors contributed to the general discussion.

Conflict of interest The authors declare that they have no conflict of interest.

Supplementary information Supplementary data are available in the online version of the paper. 

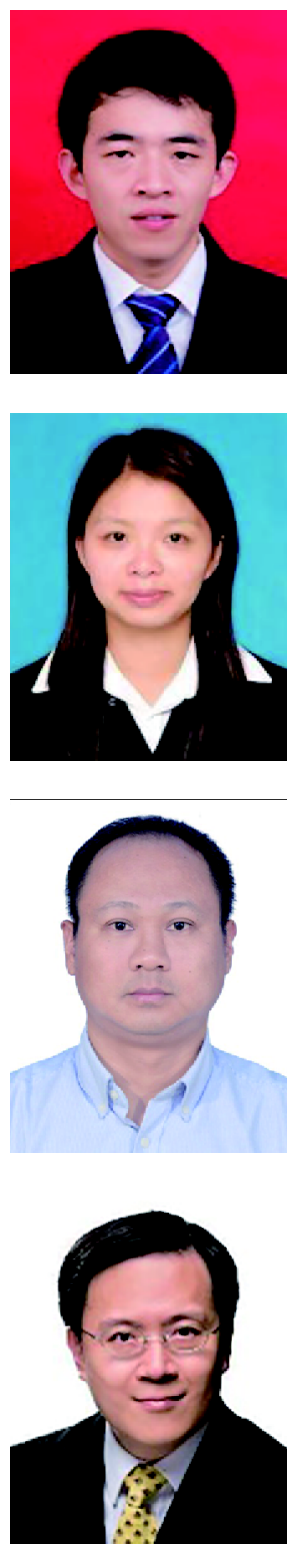

Zhengong Meng obtained his PhD degree under the supervision of Prof. Wai-Yeung Wong at Hong Kong Baptist University in 2016. He is currently a Research Associate Professor at Shenzhen University. His research focuses on magnetic alloy nanoparticles for high-density magnetic recording.
Cheuk-Lam Ho earned her PhD degree from Hong Kong Baptist University in 2007. She is currently an Assistant Professor at The Hong Kong Polytechnic University and her research interest is in functional metallophosphors and metallopolymers for light-emitting and photovoltaic applications.
Zhen-Qiang Yu received his PhD degree in polymer chemistry and physics (with Prof. Er-Qiang Chen) from Peking University in 2007 and at the same year he joined the School of Chemistry and Environmental Engineering, Shenzhen University, where he is currently an Associate Professor. From 2015 to 2017, he joined Hong Kong Baptist University as a Visiting Research Fellow with Prof. Wai-Yeung Wong. His current research interest includes phase behaviors of liquid crystalline polymers, luminescent liquid crystals and liquid crystalline functional materials.
Wai-Yeung Wong obtained his PhD degree from the University of Hong Kong. He did postdoctoral work at Texas A\&M University and University of Cambridge. He worked in Hong Kong Baptist University from 1998 to 2016 and he now works at The Hong Kong Polytechnic University as Chair Professor of Chemical Technology and Associate Dean of Faculty of Applied Science and Textiles. His research focuses on synthetic inorganic/organometallic chemistry, especially aiming at developing metal-organic molecules and polymers for organic optoelectronics and metal-based nanomaterials.

\section{半竹节虫型双金属配合物制备铁铂纳米颗粒及其图案化阵列的磁存储应用}

孟振功 ${ }^{1,3}$, 何卓琳 ${ }^{2,3^{*}}$, 王汉辉 ${ }^{4}$, 余振强 ${ }^{1^{*}}$, 朱年永 $^{3}$, 李桂君 ${ }^{4}$, 梁志华 ${ }^{4^{*}}$, 黄维扬 $^{1,2,3^{*}}$

摘要 $\mathrm{L} 1_{0}$ 相铁铂合金纳米颗粒具有较高的磁矫顽力, 其图案化阵列有望用于开发下一代磁性数据记录系统, 但是单分散铁铂纳米颗粒的 合成及大规模制备图案化阵列的制备仍是巨大的挑战. 本文合成了一种含有铁铂的双金属配合物，配合物由刚性的共平面金属中心和柔 性尾链形成半竹节虫型结构, 这种特殊的分子结构有利于机械加工中分子有序排列. 配合物用作单源前驱体经一步热解即可制备 $\mathrm{L} 1_{0}$ 相铁 铂合金纳米颗粒. 另外, 借助高效的纳米印刷技术, 对配合物溶液进行压印即可制备大规模高度有序的图案化阵列, 所得阵列在氩氢混合 气保护下原位热解, 形成规则的磁性阵列, 表明这种方式制备的磁性图案可用于磁数据存储设备. 